\title{
Agents and Spectres: Life-space on a medium secure forensic psychiatric unit
}

Abstract

Medium secure forensic psychiatric units are unique environments within the broader 'post asylum' landscape of mental health services. Length of stay is much greater, a recovery-focused care system is much more difficult to implement, and there is a paucity of suitable "step-down" services. The aim of this study was to examine how forensic psychiatric environments contribute to the shaping of recovery, by examining key features such as social interactions and agency. Here, we report on the findings from patients participating in a qualitative-visual study. This analysis forms part of larger study on staff and patient experiences of secure hospital space. In this paper, the analytical focus is directed towards two key elements of recovery - agency and relationality, using the concept of 'topology' and 'life-space', developed by the social psychologist Kurt Lewin. First, we explore how patients have relative freedom to move within institutional spaces, yet lack relational space. Secondly, we explore how life-space is expanded or compressed by the manner in which the patient's present life in hospital is connected or disconnected from their past or pending future. Finally, we discuss the implications of these findings for a recovery model within secure forensic settings, focussed on personalisation and expanded life-space. 
Keywords: secure recovery; forensic mental health; life space; therapeutic landscape; personalisation; five-year forward view

\section{Introduction}

The Five-Year Forward View for Mental Health report produced by the independent Mental Health Taskforce for NHS England (NHS England, 2016) offers an unvarnished account of the challenges for delivering effective secure mental health services. It points to a pattern of stable admissions to inpatient care, but increasing severity of needs and rising numbers of persons being detained. The report calls for care to be 'safe, effective and personal and delivered in the least restrictive setting' (p.9), but notes that due to a lack of consistency in the provision of secure mental health services, "long stays in high cost secure hospitals and delayed discharge are common, often owing to the lack of recovery-focused care and suitable "step-down" services' (p. 31). At the heart of the report is the tension between the desire to increase patient autonomy and choice (i.e. 'personalisation') and the capacity of services to enable the 'equal and collaborative relationship' (p.43) that is required to address this.

Secure mental health services, in the form of locked wards where persons are detained under a section of the Mental Health Act (commonly referred to as 'being sectioned'), are now considered a 'last resort'; to be entered only in terms of crisis, and for shorter periods of time, when acute care is required (Department of Health, 2009). Implementing 'safe, effective and personal' care is complex, and necessarily seeks a delicate balance between 
embedding safety and risk management with therapeutic provision (Curtis et al, 2013; Curtis et al, 2009; Moon, 2000). This is reflected in the design of contemporary secure units, within both general hospital and dedicated psychiatric sites, where the use of individual bedrooms alongside larger ‘community' spaces and adjacent outside green spaces is tempered with a concern for establishing 'sightlines' for monitoring patients, removing potential ligature points and minimising the potential for 'weaponising' the environment (e.g. limiting access to boiling water, shatterproof screens on televisions etc) (Connellan et al, 2013). Often changes in risk assessment can overturn the fixed elements of the built environment, as Curtis et al (2013) report in the locking of bedroom windows designed to be opened in a new build psychiatric hospital.

The relationship between risk management and patient autonomy is particularly acute within secure forensic mental health services (divided into 'high', 'medium' and 'low' security levels), where patients straddle the legal and mental health systems simultaneously. The discourse around the assessment and reduction of risks to self, others and the environment dominates service provision in these settings (Maden, 2007) and informs decisions regarding patient's lives, including their freedoms, relationships, sexuality and private intimacies (Brown et al, 2014).

Forensic mental health care pathways have a special status in the UK. The mental health sector as a whole was originally situated in the 'forbidding' system of 'locks, bars and padded cells' located in enormous psychiatric 
asylums, whose spatial character has been historically mapped by Chris Philo and Hester Parr (Philo, 1987; 1995; Parr \& Philo, 1996). The programme of closures of the county asylum system initiated in the latter third of twentieth century, as part of the shift towards 'care in the community', transformed this imposing building stock (often in prime urban locations) into college campuses and residential developments (see Moon et al, 2015). But forensic units, which maintained the practice of separation and confinement, were either left untouched or relocated to new purpose built facilities, typically within larger hospital grounds. They persist as 'spectral presences' (cf. Moon et al, 2015) of a prior approach to mental health within the contemporary 'post-asylum' landscape (Wolch \& Philo, 2000; Philo, 1997).

Since patients are typically transferred into or out of secure forensic care from the prison estate - often abruptly (Smith \& Garcia, 2012) - hospital wards are constructed around carceral designs of locked doors and high walls. Secure forensic wards are considerably less 'permeable' than other kinds of psychiatric wards (see Quirk et al, 2006), in that there are greater restrictions on overall movement around the hospital site, visitors, and patient access to mobile phones and the internet. Some forensic patients are subject to very stringent restriction orders that effectively confine them within the limits of the ward, creating issues around access to green spaces (Roberts et al, 2008). These orders are made by criminal courts under section $37 / 41$ of the Mental Health Act, which specifies secure care in a hospital rather than prison environment and placed restrictions on movement. Although the majority of forensic patients do eventually leave inpatient units after 2-5 years, a 
significant minority remain detained for prolonged periods, of up to 15 years and beyond (Coid et al, 2001; Edwards et al, 2002, Brown and Fahy, 2007; Amar et al, 2011).

Despite these clear obstacles, a movement towards implementing the kind of personalized 'recovery-focused' care called for by the Mental Health Taskforce within forensic mental health settings has been gaining pace (see Williams et al, 2012). The 'recovery model' that underpins this approach sees the 'subjective experiences' of mental health service users, in particular those related to 'optimism, empowerment and interpersonal support' (Warner, 2009: 374) as critical to not merely a remission of symptoms, but as establishing a trajectory towards a longer-term adjustment to living with mental health issues, which involves social inclusion and a positive sense of identity. Implementing what Drennan \& Aldred (2012) call 'Secure recovery', can take a variety of forms, which are typically clustered around organizational interventions, such as greater patient involvement in strategic decision making or therapeutic interventions, such as creating 'recovery groups' (Miles, 2012).

The aim of these interventions is to increase the participation of patients in the daily life of the ward and to develop relationships amongst service users and staff. However, as has been previously demonstrated by Brown \& Reavey (2014), this can be in tension with an organizational focus on current matters at hand - or presenteeism - that does not necessarily provide a means for patients to situate their current experiences in relation to their past and their aspirations for the future. Brown \& Reavey develop this concept through 
empirical work on a medium-secure forensic mental unit that shares many characteristics with the one studied in this present paper, but they are informed by informed by classic and contemporary ethnographic work in the prison estate which has emphasized the institutional tendency to direct focus at the present (e.g. Cohen \& Taylor, 1972; Moran, 2015). Given the emphasis in recovery models on 'hope' as a driving force (Leamy et al, 2011), placing self-conceptions of current agency within a broader temporal and spatial structure is critical for understanding the capacity of forensic patients to move beyond or 'step down from' secure care. Moreover, there are limits on what kinds of relationships are facilitated. The nature of work patterns on the majority of secure forensic ward means that nurses typically do not have the time available to develop close relationships with patients. There are also strict norms around the sorts of relations patients may build with one another, with close personal or intimate relationships discouraged - despite the lack of any formal policy or best practice around this issue across the system (Ravenhill et al, forthcoming). Finally, the focus on the present fails to acknowledge relationships that span across physical boundaries - i.e. personal relationships, family connections to the broader community - that are crucial to producing meaning around current detention, and upon discharge (see also Reavey et al, 2017).

In this paper we examine the effects of presenteeism on forensic mental health patients' sense of agency and orientation to broader relationships during the course of detention on a medium-secure unit. We develop a model of agency, based on the work of Kurt Lewin, which treats experience as 
constituted through relationships - both to others and to the sociomaterial environment - rather than a matter of inner, subjective perceptions. As we will argue, these relationships can be thought of as topologically structured, rather than immediately present, in a way that complexifies the spatial and temporal production of experience. This approach builds upon a turn within Psychology that has sought to treat experience as a 'more-than-cognitive' phenomenon, which is relationally constituted through the embodied engagement of persons with their social and material worlds (see Bell et al, 2017; Cromby, 2015; Brown \& Reavey, 2015). Bringing this approach into dialogue with existing work on the built environment in psychiatric care and work on 'therapeutic landscapes', allows us to see that the psychological limits of the life of the forensic patient extend far beyond the immediate secure setting in which they are detained. Furthermore, it provides insight into how recovery approaches might take a broader view of the kinds of relationships that require support.

\section{Lewin, Life Space and Agency}

Kurt Lewin's work in the early 1930s rejected a mechanistic approach to behaviour as under the control of external stimuli in favour of a field theory approach (see Lewin, 1936). There is much in this work that prefigures contemporary psychological interest in process thinking (e.g. Stenner, 2017; Brown \& Stenner, 2009; Brown \& Reavey, 2015) and in 'relational geographies' (e.g. Massey, 2005; Malpas, 2012). Lewin's key concept was 'life space' defined as the 'totality of facts which determine the behaviour (B) of an individual at a certain moment. The life space $(L)$ represents the totality of possible events ... It can be represented by a finitely structured space' 
(Lewin, 1936: 216). A 'fact', for Lewin, is an elementary psychological unit, something perceived, felt or thought. Facts are relationally constituted - they are as much 'in' the field as they are 'in' the person. The totality of relevant facts available at any moment structures the field of possible actions, or the current psychological limits of experience such that 'what is real is what has effects' (p.19). One of the key features of life space is that it is topologically organized. The relationship we have to facts and behavioural possibilities is not reducible to measurable distance. What this means in methodological terms is that understanding behaviour requires a mapping of the totality of relationships that are in play, not simply those that are in immediate spatial proximity.

Relationships clearly extend over time. Lewin argues that present behaviour needs to be situated with respect to a mobilisation of the past and an anticipated future, which become part of the present 'psychological field' (Lewin, 1997: 207). Just as spatial remoteness is less important than relationships themselves, so temporal distance is less important than the ongoing degree of connectedness or relevancy between past and present events. Current action needs to be inserted into a vector of interactions, which have an ongoing meaning in understanding the present moment. Every movement through the psychological field that constitutes life space has an effect back upon the field, since it shapes the possibilities for further movement at each point. Our actions do not simply bring about states of affairs in the present, they also realize or 'make actual' future possibilities (see Brown \& Reavey, 2015). We may be more or less aware of these possibilities 
in the course of our action, but they are nevertheless active in shaping what we do. The capacity to envisage a broader range of possibilities that might be brought about through one's actions extends the boundaries of life space.

On this basis, we define agency as the expansion and contraction of life space. If life space is the psychological field of possibilities that exists at any given moment, then sensitivity to the range and extent of these possibilities is, for practical purposes, what constitutes a sense of agency. The more that a person feels connected to broader range of relationships- those that are spatially remote, different aspects of the past and possibilities for the futurethe greater their sense of agency is likely to be and vice versa.

\section{Space and Time in the Built Environment and Therapeutic Landscape}

The quality of the built environment shapes the delivery of secure inpatient mental health services and perceived well-being amongst patients (see Reavey et al, 2017 for recent review). Whilst the systematic review by Papoulias et al (2013) found no overall causal connection between psychiatric ward design and clinical outcomes, it confirmed an oft-repeated claim that creating more private spaces increased patient well-being. The critical element appears to be the ability of patients to exercise some degree of control over their environment, including choice over where to engage in social interaction (Payne \& May, 2009). New build secure units, which incorporate private bedrooms along with multi-purpose social spaces have been associated with reduction in service user length of stay and use of seclusion rooms (Lawson et al, 2003). What the concept of life space adds to 
our existing understanding is the idea that patients engage with the built environment in terms of it how shapes relationality. For example, markers of detention, such as locked door and high walls, may not necessarily act as the limits of psychological space (see Moran, 2015), if relationships to others can be maintained through these porous boundaries (e.g. through telephone calls, passing contraband etc). Conversely, freedom of movement within the space, such as the use of outside spaces and communal areas, might well diminish rather than expand a sense of agency if they do not strengthen relational possibilities. The built environment should then be explored from the perspective of the relationally defined life space of the patient, rather than in terms of its spatial affordances only.

The conceptual framework of 'therapeutic landscapes' (Gesler, 2003; Curtis, 2010; Wood et al, 2013) adds the important additional dimensions of social relationships and symbolic meanings to that of the built infrastructure. The work of Sarah Curtis, Victoria Wood and colleagues has been pivotal in demonstrating that the space of inpatient psychiatric care facilitates and constrains relations between staff, patients and mental health carers (e.g. Wood et al, 2013; 2015; Curtis et al, 2007, 2009). In particular, their description of how the meanings of risk and surveillance may be subject to negotiation as spatial practices change (Curtis et al, 2013), shows that shifting symbolic dimensions of the built environment are as relevant as its material properties. However, as Kearns and Moon (2002) argue, there is a tendency to over-valorise the positive aspects of therapeutic landscapes, which acts to distract attention from landscapes that are seen as corrosive of well-being 
(e.g. urban 'sink estates', impoverished rural areas). Instead of using a therapeutic/non-therapeutic distinction, there may be greater value in following Moon et al's (2015) proposal to identify the 'relational dynamics' through which particular aspects of a landscape shape well-being (see also Duff's 2012 analysis of the relational features of 'enabling spaces').

What the life space perspective then brings into focus is precisely these ways in which experience is relationally constituted within a therapeutic landscape. If, as Lewin (1997) argues, present experience is shaped in relation to both the mobilisation of a psychological past and the anticipation of a psychological future, then an understanding of how present social interactions and sensemaking fit within the past and future possibilities is crucial to understanding how patients engage with the therapeutic landscape. As we will discuss, this is an issue when the institution is predominantly focused on the present.

The material discussed here is drawn from a larger study of a medium-secure forensic unit within Greater London. The study was concerned with the experiences of patients and staff of a relatively newly built set of wards. Here, we focus purely on material gathered from 'patients' to illustrate the reach of their relational world. We will show that whilst their experience is constituted through relationships that stretch beyond the boundaries of the unit, the institutional focus on the present accords efficacy and concern only to immediate relationships. This leaves patients with a sense of their broader 
agency as spectral - i.e. that their past or future personal experiences do not inform their current behavioural possibilities. We argue that this is in tension with the desire to promote recovery-focused mental health care, highlighting the need to reconsider how the past and future of patient lives are taken into account during the course of prolonged hospital stays.

\section{Context and Method}

The qualitative material analysed here was collected as part of a broader project conducted with a large, purpose built, medium-secure forensic mental health unit in Greater London. The unit is located within a large wellestablished hospital site, which includes a wide range of other psychiatric units, including other locked wards and low-secure pre-discharge wards. The overall aim of the study was to examine how the built environment of the new unit shaped specific experiences of distress amongst patients. The research was primarily based around interviews with 40 staff and patients, along with observations recorded during the periods of fieldwork. Observations were recorded in researcher diaries, and then used to supplement interview material where relevant. Observations relating to staff and patient movement, behaviour and the overall atmosphere of the ward were recorded, either during or post visit. We use the term 'patient' since at the time of the study those participants were detained in medium-secure care within a forensic pathway. Whilst this term is technically accurate, we are aware of the problems with this term and in other contexts would refer to 'individuals who use services' or 'individuals who live with distress' (see Cromby, Harper \& Reavey, 2013). 
The specific research reported here is drawn from 20 interviews with patients, each of which was carried out by one of the five authors and lasted between 35 to 90 minutes, supplemented by observations of ward practices (see above). Before access to patients or staff was permitted, ethical approval by the local NHS Research Ethics Committee and London South Bank University Ethics Committee was required, and subsequently granted.

The interviews used a photo-production methodology to elicit more specific and rich responses relating to the environmental aspects of the unit. This approach has been used in the context of examining the therapeutic qualities of a variety of natural landscapes, including blue and green spaces, as well as medical settings (see Coleman \& Kearns, 2015; Reavey et al, 2017). This approach in particular affords a more direct engagement with the phenomenological detail of the space itself in these studies, which was perceived to be advantageous to thoroughly grounding the self in environmental context. Patients were asked to produce a series of photographs of places around the unit that were of interest or importance to them, which they did whilst accompanied by a member of staff. The photographs were then printed as a booklet and subsequently used as the basis for the interview conducted between one to two weeks later. The interviews followed a semi-structured format, to the extent that a schedule developed by all researchers was used to guide the conversation. However, the interview was guided primarily by the participant's engagement with the visual material, such that the order of questioning was led by the participant's discussions via the photographs they produced. Each of the authors 
conducted interviews and found that differing levels of medication impacted the participant's ability to engage in a sustained conversation. Participants on heavy medication sometimes required more prompting than participants who were on little or no medication (n.b. this only applied to patients on the 'Personality Disorder' wards). Overall, participants engaged with the visual material and interview questions, with varying levels of engagement with material of a more personal nature. Each interviewer agreed in advance that the interview would be participant led and that deep prompting into life history and mental health would not be appropriate, and could even be harmful. This was reflected in the ethical clearance.

Participants were asked to discuss the photographs, in terms of their thoughts and feelings about the specific space illustrated, and their experience of the hospital more generally. The use of visual material alongside verbal data is advocated within a growing body of work in psychology and psychosocial research (e.g. Reavey, 2011; Rose, 2001; Reavey \& Johnson, 2017). Visual materials are typically thought to provide more effective prompts for participants to discuss the settings and context of their experiences, since they contain clear spatial cues (see Bolton, Pole \& Mizen, 2001; Knowles, 2000a; 2000b). In this research, the photo-production technique was intended to support participants articulating aspects of their experience that might be difficult to put into words, such as feeling associated with particular spaces on the ward and embodied experience (see Brown et al 2011; Gillies et al., 2004; 2005). The method was also intended to empower participants with regard to the structure of the discussion and to offset some of the well-known effects of 
medication on the interactional abilities of psychiatric patients by providing a clear point of reference.

The interviews were digitally recorded and transcribed verbatim. The participant's name was replaced by pseudonym, chosen by the researcher. The photographs were primarily understood as prompts, and hence given meaning by the participant in the context of the interview, rather than treated as data to be analysed independently (Reavey \& Prosser, 2012). Our reading of the audio material was guided by the overall research question of how patients experience the hospital as 'life space', with specific attention paid to the ways in which they move and engage with all public and private spaces. The concern with space was informed by our theoretical position, developed across a number of studies, where distress is treated as shaped and mediated by spaces and setting, which create possibilities for action (see Reavey, 2010; Tucker, 2010; McGrath, 2012; McGrath \& Reavey, 2013; 2015; Brown \& Reavey, 2015). This is a psychosocial approach that sees individual experience as situated in wider social material contexts.

After notating and coding the material with these questions in mind, the data were re-organised into themes and subsequently considered in the light of literature that could assist in contextualizing the analysis. A thematic decomposition (Stenner, 1993) approach was used to analyse the data, which sought to identify processes through which agency was understood and experienced, located in particular themes around space. This thematic 
decomposition was achieved by following a number of stages of analysis that are commonly found in many forms of qualitative analysis (Willig, 2008). This involved familiarisation with the data via repeated readings of the transcripts, generating initial codes by paying close attention to meanings embedded in every line of talk, followed by matching the initial codes together to form candidate themes and sub-themes. Each of the authors was involved in discussions around whether the theme titles and definitions adequately captured the essence of the data.

The analysis that resulted was 'theoretical' insofar as a concern with the constitution of agency and life-space was present from the initial reading and notation of the data. Nevertheless, the interpretation produced was also 'inductive', in the sense that the final account produced was based on a close reading of the material, and was not based on fixed notions regarding any final themes that might emerge from the data. The interpretative process further involved exploring the implicit meaning of the material, rather than a more descriptive reading. The validity of the findings was addressed using conventional qualitative procedures, including group analysis by key researchers and peer review, to ensure the analysis was sufficiently grounded in the data (Creswell \& Miller, 2000). In order to physically situate the analysis for the reader, a diagram of the unit has been provided below. The unit has been designed so that there are lines of sight at all times. It did not escape the staff's attention that the unit resembled a 'panoptican' which enabled clearer patient observation, which in line with Michel Foucault's argument increased self surveillance in patients (Foucault, 1995). 
Insert Figure 1.1 here

\section{Findings: The expansion and contraction of life space}

Our analysis identified a number of institutional practices within the forensic mental health unit that shaped how agency was constituted for and experienced by patients. We focus here on practices that appear to promote and support agency, and those which seem to restrict and limit it. The central issue here concerns the interplay between the physical space of the hospital setting - primarily the ward where patients spend the majority of their time and the psychological 'life space' of the patient. This gives rise to a series of distinct spaces of experience described by participants - public, private, group and personal - which have different relationally defined fields of possibility. The expansion or contraction of these fields is, we argue, what constitutes a sense of agency.

\section{Public Spaces}

The medium-secure wards on the unit were constructed around large open central areas, with lounge, dining and games zones, and doorways to a communal outside space. Smaller rooms used for meetings and group activities were positioned around the main area, along with kitchen spaces (although these latter were relatively under-used due to issues with providing appropriate staff cover). The nurse's station, a small locked office with large windows, was placed at the centre of the ward, from which sightlines could be maintained across the majority of the space. Patient bedrooms - around 18 
per ward - were built along wide, high ceilinged corridors radiating from the central area.

The physical space of the ward encouraged spatial closeness through the positioning of furniture and the clustering of routine activities, such as eating and watching television within the central communal area. However, a lack of regular activities punctuating the day, aside from mealtimes, meant that patients moved around the ward without an apparent sense of purpose or much by way of relational engagement either by staff or other patients. Whilst the openness of the space was designed to facilitate interaction, this was not experienced as relational closeness. Patients often described feeling neglected by staff, and remote from the lives of the other patients. A common sight was of patients approaching the nurse's station to make requests or demands on staff who were engaged in administrative work:

Researcher: Okay, why did you put this in? [photograph of bedroom] Joshua: $\quad$ Cos the staff frustrate me ... It's just they ignore me, they go around, they say that they can't speak to me but then have one-to-ones with other people ... feel as though I'm being ignored.

R: $\quad$ So you've taken this of the window to the office with people standing on the other side? [picture of the nurses stations]

J: I think they're on the phone, so I couldn't actually take a picture of the office ... so you have this bit where there's a separate office and then you're kind of seeing stuff but not - but not 
necessarily getting anything? (laughs)

In this extract Joshua refers to photographs of his bedroom and of the staff office on the ward, in describing his sense of being ignored by staff who he feels are either preoccupied with other activities, or with other patients. His feelings of frustration are illustrated for him via the image of a staff member making a telephone call on the other side of the locked office door - whilst they are physically close, just behind the glass, they are not relationally close.

Much of the time spent in public spaces was described as akin to 'waiting' for something to happen. Our observations coincided with such a description. We spent prolonged periods of time on wards where patients were sitting and watching television, with minimal interaction. Many activities, such as leave to the hospital grounds, were dependent on the availability of staff to facilitate (see Wood et al, 2013). This often meant patients competing for attention with whatever was occupying nurses in the office. Frustrations were then expressed by patients constantly knocking on the door of the nurse's station, and in turn by nurses apparently using the station as a space to retreat from interactions, to attend to ever increasing administrative tasks.

In the following extract, the participant describes what happens when frustrations on the ward turn into open conflict:

Denise: $\quad$ You have the problem of laundry, you know, fights over food. Patients always fight in the queue for food. I think it's the staff, 
the staff is the problem. They don't have much time, you know.

Researcher: Do they do things with you on the ward?

D: Well, you know, we used to do board games and all sorts of things which ... As I say they just can't help when we start arguing with other patients, you know? And staff don't interfere ... I don't like being unsafe.

Denise claims that staff tend not to intervene when verbal conflicts erupt between patients. This leaves her feeling 'unsafe' in the public areas of the ward at this time. Conflicts with other patients over apparently trivial matters such as which channel the television was tuned to, or around choices made from the weekly meal menus, were commonly reported, along with a tendency to mistrust the motives and behaviour of some fellow patients (particularly those recently admitted to the unit). The lack of structure to activities on the ward appeared to exacerbate such conflicts, since individual demands and needs tended to usurp any sense of shared interest or mutual support. So whilst the public spaces afforded a greater sense of spatial autonomy (as patients were usually free to move around as they wished), this was accompanied by feelings of neglect, lack of purpose and of being, at times, unsafe, with a consequent diminishment in a sense of agency. One way of dealing with these kinds of issues, and re-asserting agency and control, was to retreat to the safety of a private bedroom:

Researcher: What are some of the feelings that you have in this particular space? [photograph of bedroom] 
Derek: Um, well I have a sense of safety. I almost kind of, feel more relaxed. Whatever happens outside of the room, quite often I try and leave outside of the room. But sometimes there's a bit of overspill and it comes inside of the room and, um, comes inside of me.

For this patient, their bedroom constituted a refuge from the stresses of ward life. Derek describes attempting to maintain a boundary between his private space and the public space of the ward. But this boundary is semi-porous - it is not always possible to leave things outside, and this is experienced as a form of emotional contagion ('it comes inside of me'). Whilst the shared ward space provided a greater literal space of movement, his bedroom afforded a site of greater control over his psychological boundaries (see also Reavey et al, 2017). The relatively more confined area of the bedroom was then richer with respect to life space.

\section{Private Spaces}

The majority of patients in the forensic mental health care pathway will have experienced detention in the prison system. In the UK, practically all prison cells are shared. By contrast, following a person-centred approach, all recently designed secure care wards have individual bedrooms, which are intended to foster a sense of autonomy, peace, and encourage well being (see NAPICU, 2017). Individual bedrooms offer considerably more privacy than both prison cells and the fabric walls of the older style hospital wards. Unlike prisons, patients are typically not allowed to socialise in one another's 
bedrooms, and physical intimacy between patients is strictly prohibited. But despite this relative privacy, bedrooms remain spaces of continuous behavioural monitoring, with staff routinely checking patients either through door viewers or directly by entering the bedroom, during both day and night time. The possibility of being disturbed by a staff member at any point is a source of anxiety for many patients:

Leon: $\quad$ In prison when you're locked up you can't go out, but when you're here you can come out at any time. But sometimes you wake up out of your sleep for stuff. I don't like that that much. It's just, it's like external stuff like maybe stuff you can hear, like through the window or through the door, you know. And, and you can't see the person. I know that behind the curtain there's a, there's a peephole but I normally block it up. And they [staff members] complain about that, saying you're not allowed to. But I don't like being like - feeling like I'm being looked at.

Leon draws a contrast between being confined in a prison cell with the relative freedom of movement on the ward. But he tempers this with a concern over being observed at any moment. Whilst the process of continuously monitoring patients reflects the ever-shifting balancing act between the management of risk and maintaining a therapeutic environment in psychiatric care (see Curtis et al, 2013; Moon 2000), it also demonstrates that the relationship between the public and private is reversible. Patients can feel alone and ignored in the common areas of the ward and in the presence of unseen others and watched 
when in their bedrooms. This suggests that the mere physical proximity to other persons is not the decisive factor in how relationships are experienced on the ward. Many patients emphasised their preference for spending time in their bedrooms rather than in communal spaces:

Peter: $\quad$ This first one [photograph of bedroom] it's in the room that I was in round by the office, and um, it's got a picture of my hi-fi where I listen to music and just chill out in there. And there's ward activities, some of them I do. Some of them I don't do. This is where I spend most of my time, in my room.

Researcher: Do you use the outside space?

P: $\quad$ NO

R: $\quad$ You don't go out there? Why not?

P: $\quad$ Just can't be bothered with it.

Peter here emphasises some of the pleasurable activities, such as listening to music and 'just chilling out' that are afforded by having a private space. This is contrasted with the purpose built outside spaces on the ward, which were designed to promote engagement with the environment. Peter emphatically states that he 'can't be bothered' with that particular space. This might be interpreted as a withdrawal from social interaction and relationships. However, if life space is to some extent distinct from physical space, then the relational aspects of activities such as listening to music acquire importance. In the following extract Vincent describes how he regularly tunes in to specific radio 
stations in response to a question about a photograph of a radio in his bedroom:

Vincent: $\quad$ That's my radio there...it's a way to keep contact, keep up with things what' s going on outside ... I'm no longer a DJ, but used to be when I was younger. Now I'll be enjoying the music in the crowd, instead of having to worry about what goes on next or what to play next, but I like reggae music. I like the seventies and the eighties. Those are the times when things was all right, apart from when the riots happened, everything was running smoothly.

For Vincent, listening to the radio both connects him to the outside world and serves as a symbolic act of solidarity, from one (former) DJ to another. Whilst his physical world remains bounded by the bedroom, his relational world is expanded exponentially through the radio. As Victoria Knight (2016) makes clear in her study of television viewing in prison, there is an emotional and relational complexity involved in this engagement with media that both enables an extension of social relations beyond the immediate setting and serves as means to overcome some of the physical restrictions of detention.

Bedroom spaces are then complex. They are not exactly private spaces, since the immediate outside of the ward 'comes in' through noise pollution and emotional contagion, along with the ongoing monitoring and surveillance by staff (and other patients, who also make use of door viewers to observe 
their neighbours). But they also offer a richer relational life space than that which is available in the communal areas of the ward. Patients' bedrooms can then be seen as facilitating a double movement of both expansion and of contraction of life space. If agency is expanded through a mediated relational engagement beyond the ward, through experiences such as listening to music, it can also be contracted through rendering the patient as isolated object available to the gaze of others.

\section{Group Spaces}

Social interaction between patients in the unit was promoted through group activities tackling issues such as drug awareness, anger management, cooking, occupational therapy etc. These activities potentially served the dual purpose of a) engaging in a form of treatment that would encourage selfreflection and b) reducing risk and serving as a marker of rehabilitation. However, group activity was most often seen as repetitive and futile, or something that patients' 'did' passively, to further their exit from the institution. Rather than deepen relations between patients, they were something one drifted into, several times if need be. In terms of agency, the main purpose of the groups perceived by patients was that of increasing the likelihood of earlier release, rather than strengthening current relations:

Leon: Because there's not much going on...there's activities, there's a food group during the week, but I want, - you have to do them to get out. So it doesn't matter how you feel about it, you have to 
do it. But personally, l've done them quite a few times, each one of them. Like quite a few times. Like drugs awareness and the DBT, RNR, ART . Um, all of them, well they don't do anything, they're no good. And I done them about four or five times ... facilitating one group. The only thing that really goes on between the patients is watching TV, having dinner together.

* DBT - Dialectical Behaviour Therapy; RNR - Risks Needs Responsibility model; ART - Anger Reduction Treatment.

Leon describes the groups as providing little by way of additional insight into his experiences ('they don't do anything'). Whilst they may serve to break up the day, they provide little sense of progress. Our sense was that patients were not able to meaningfully link the content of the activities to either their life prior to admission, or their future after discharge. This lack of connection reinforced the presenteeism of the ward, particularly when, as Leon states, the same group activities were repeated. One serious difficulty experienced by patients around group activities was being placed with other patients, without consideration of prior offences or history - i.e. patients who are victims of sexual assault being placed in a group with a sex offender. For some patients, such enforced relationality with individuals whose very presence undermined any sense of agency was a serious problem and exacerbated distress:

Joshua: We do ART and PD (Personality Disorder) group. I find that difficult cos the voices were kicking in and I couldn't focus and I 
was getting really angry. So I didn't - I wasn't in there long. I don't like a lot of people. It's stressful where they're rapists and paedos as well. Not good with that, cos I've been raped in the past. So I can't deal with being around them.

R: $\quad$ So is there any kind of acknowledgement of that by the staff, do you think?

J: $\quad$ Yeah. They're helping me, um, find ways of dealing with it. At the moment I'm dealing with it by pretending to be happy and whatever around them, but what I wanna do is hurt them. They have to talk about what they did and why they did it and whatever, and I can't sit there and listen to that.

What Joshua experiences in the groups is an enforced relationality and a reinforcement of the present, at the expense of the past. Rather than feeling part of a shared project of gaining insight, he experiences a diminution of agency, accompanied by feelings of being unsafe and having to mask deep anger. This is exacerbated by Joshua's experience of hearing voices, which prevent him from focusing on the present interaction, heightening his distress. As Brown \& Reavey (2015) have argued previously, the way in which 'wellness' and 'co-operation' are typically performed in medium-secure wards does not require reference to the patient's past, often including the index offence itself. This amounts to a severing of the connection between past and present. If agency is achieved in part via our ability as persons to understand the relationship between our present and past actions (see Reavey \& Brown, 2006; 2007), the group activities enact a spectral version of agency. Patients 
are present to one another and perform themselves as 'engaged' or 'happy' during group activities in order to be seen as adherent with their treatment plan, but are either unable to connect these present activities in any meaningful way to their past, or, at worse, feel that these activities are disruptive and threatening to making sense of how they came to be where they are.

\section{Personal Spaces}

Patients in medium-secure care are subject to observational monitoring on a daily basis. Ward staff update individual records with notes on the behaviour, mood and symptoms of each patient in line with their personal care plan. This follows a personalisation agenda that is meant to ensure that whilst patients may be in the same physical space, their experience of care is fitted to specific individual needs (Curtis et al, 2007; Gudjonsson et al, 2010). However, the extent to which a personal space of care is constituted within the ward is questionable. The details that are observed and recorded by staff are not concerned with specific life experiences and biographical matters around the individual patient, but rather context-free descriptions of the patient's health and current behaviour. These are often noted by cutting and pasting text within electronic records from one day to the next. Moreover, whilst the majority of inpatient psychiatric care uses a clinical formulation approach to develop a narrative around the person to guide treatment, a common complaint amongst patients is that they are not asked about their life experiences and history during admission (see Brown \& Reavey, 2015). During their detention under a section of the Mental Health Act, the life course 
of a patient is not the primary focus of care, which is instead concentrated around the management of symptoms and the stabilization of mental health. The perceived lack of concern on the part of the institution with patient biography was found by some patients to be troubling and counter-productive:

Leon: Knowing me and my history makes a difference cos they know why you're angry. Whereas if you was just to come onto the ward and see me angry or something and shouting they probably would go, "That guy's a madman, l'm out of here." But another person would know why so they would deal with it differently. But my primary nurse, I have a good relationship with him and he knows me well enough to know that there would be a reason instead of just me getting up and doing it for no reason.

Leon emphasises here that knowledge of his past is essential to properly understanding his current actions, which would otherwise just be seen as those of a 'madman'. Observation needs to based on a 'good relationship', such as he has with a primary nurse who he has known across different hospital units. In this case, a shared history with a member of staff seems to have come about fortuitously. Organizational issues around shift patterns, staff turnover and patient mobility often forestall being able to build a relationship in this way. There simply is very little space or resource to explore and examine the patient's past, which is typically not seen as critical to stabilising mental health on the ward. Moreover, some therapeutic 
interventions, such as Dialectical Behaviour Therapy, actively discourage patients from 'dwelling' on past events (Scheel, 2000). This results in a compression of life space, which discounts relationships that extend across time and space and focuses predominantly on current interactions. Few patients describe themselves as having 'friends' on the ward, and where this term is used it invariably refers to a staff member who is known from a previous institution, as in the case above, or to a health care worker whose responsibilities are not primarily focused on monitoring the mental health status of patients.

Personal space - the sense of being able to express one's specific needs and history - depends upon building relations with others, and being able to create continuity between present actions and past experiences. This expands rather than compresses life space, and in so doing offers possibilities for selfunderstanding that transcend the institutional logic of stabilising health and managing risk. By contrast, when there is a discontinuity between past and present as a consequence of patients being either unable to maintain relationships or reflect on the relevance of the past, there is a tendency to offer idealistic images both of the past and future, where the present is considered as an interruption. The following extract comes from an interview with a patient who claimed not to understand why he was currently detained . When asked about his aspirations for the future, he offered the following:

Ray: $\quad$ Yeah. I just want to get out there and see my son and my daughter ... really, really badly. But, you know, I don't want to 
get upset, I won't let it happen again. But if I see my son and my daughter, If I do get emotional I probably will cry when I see my son and my daughter when I ain't seen 'em for a long time. And going to the seaside, (name of town) and live down there. And have them come down there and have a nice flat in where my dad used to live, have somewhere like that, in a nice quiet street, hear the seagulls and the sea front just down the road. You know, and stuff, and just survive. I just want to see my father in my life, you know, I want to see me Nan and me uncle and all me family.

Ray talks fondly here of an anticipated reunion with his children, which will serve as a prelude to a return back to his hometown where he will 'live his life again'. He describes a relatively simple life and the resumption of contact with members of his family who have not been part of his life for some time. What is strikingly absent here is any sense of the material difficulties or the interpersonal obstacles that may be prevent this return, or, indeed, any reflection on whether his children and wider family might welcome him back. Ray's version of his agency in the present relies on a notion of things not having moved, including the people who populate that past. He focuses on his own potential emotional reactions, but not those of his children or relatives.

Idealised images of the future of this kind are associated with a disconnection from the past. In this case, Ray has been detained for a considerable amount 
of time, and claims not to understand how this is related to his index offence ('I haven't done anything out of the ordinary like, um, anything wrong you know ... keeping me away for no reason at all, you know'). He is, in effect, 'stuck' in a limited psychological life space that is constituted primarily around the present. The past has become frozen in time in a way that makes it difficult to imagine the future as anything other than the resumption of his life exactly as it was. The future would thus involve a 'return' to a past that had not altered over the course of many years. Later in the same interview, Ray comments:

Ray: $\quad$ You know, I remember [my son] when he had a little boy's voice, his voice suddenly changed, you know. But when I get out I just hope he looks the same as when he was a little boy, you know.

Here he imagines a son who has not changed over the years, who would look, talk and act the same. Lewin (1936) uses the term 'quasi-conceptual' to refer to the expansion of life space through the capacity to imagine worlds beyond the immediate situation. For Lewin, these imaginings can have the status as 'psychological facts' equivalent to those provided by the immediate environment. In Roy's case, he is limited to a vision of the future which is based on an impossible repetition of a past that is entirely static and unchanged. Again, this is a spectral form of subjectivity, where an inability to fully engage with the present arises from a disconnection to the past, and from relationships that go beyond immediate circumstance. Whilst the physical space of the ward itself may offer a relatively open space for 
movement, for the patient, the space of conceptual possibility - what they might become, what futures they might imagine - is limited.

\section{Discussion}

Personalised recovery focused care is currently promoted as the means to reduce inpatient stays in secure psychiatric hospitals (NHS England, 2016; NAPICU, 2017). The findings from our study demonstrate that there are significant obstacles presented by the current practices and operational capacity of this particular medium-secure forensic unit to the implementation of 'secure recovery'. Whilst the empirical material discussed here is limited to one site, this purpose built unit is at the forefront of current thinking and practice around secure psychiatric care in the UK, and had been designed with extensive consultation with both staff and patients. It therefore reflects much of the 'state of the art' to be emulated for care in this area. The findings are also broadly in line with research on other units (Mezey, et al, 2010; Turton et al, 2009; Brown et al, 2014; Brown \& Reavey, 2015; Reavey et al, 2017; Ravenhill et al, forthcoming). The dual aim of the unit, which is to support patient autonomy and choice whilst maintaining appropriate levels of risk reduction and security, may lead to a compromise in patient engagement with the therapeutic aspects of the landscape in which they are detained.

This is due in part to the way in which 'autonomy' and 'agency' are understood in these settings. Current design practice in secure mental health posits that the psychological is a subjective realm that is distinct from but nevertheless to some extent mirrors the physical environment, thereby conflating an opening up of physical space with an increase in patient's sense 
of agency. As our findings show, this can result in a limited or 'spectral' agency on the part of patients, who feel that the choices they can make in engaging with the environment are not especially relevant to their recovery. The original contribution of our research is to make the case that psychological space within a forensic psychiatric unit - 'life space' in Lewin's (1936) terms - is neither 'in' the person, nor 'in' the environment, but rather in the 'field of possibility' that the patient experiences. This is constituted through the relations that are afforded within the ward. These relations can extend over space and time in complex ways that overcome the physical constraints of living within a secure environment. Indeed, one of our key findings is that patients can experience the rather modest private spaces of their bedroom as being relationally far richer than either the public spaces of the ward or the outside spaces available to them. We need to explore relationality as something different to simply creating proximity to others - as we have seen here in the problems that emerge from the 'forced relationality' of compulsory group activity.

We propose that a topological mapping of the relations that give meaning to the life space of a patient could strongly inform design processes. Forensic psychiatric units are 'outliers' within the broader post-asylum landscape, in retaining the carceral architecture of the former asylum system as a 'ghostly presence' within modern mental health care (cf. Moon et al, 2015). Current approaches to managing this historical legacy focus on facilitating immediate relationships within the limited physical space of the unit, and promoting engagement with the environment through control of light, movement and 
open spaces (Drennan, et al, 2014). But these relationships sit within a broader range of relations that extend both spatially and temporally beyond the boundaries of the unit (Brown and Reavey, 2015). We need to better understand how life space interacts with physical space and the therapeutic landscape to create specific experiences of relational closeness and distance, and how changes in these relationships facilitate and promote recovery. For example, if patients feel isolated or unsafe in public areas, or bored and uninterested in outside spaces, this suggests that these spaces need to be reconfigured to allow broader relationships to be made visible and meaningful. Equally, if patients do feel that their private bedroom space enables them to better explore broader relations through engaging with media such as music, radio or (in some cases) personal televisions, there is a case to be developed around the greater use of media and digital technologies in secure care. However, this needs to be set against the view that such technologies normalise more restricted detention (see Knights, 2016) and with the need to manage risks in relation to potential offending behaviour (Dernevik, et al, 2002.

Patients on the unit we studied found the 'presenteeism' of ward practice problematic. Psychiatric institutions premise their claims to 'know' patients on a continuous recording of daily behaviour. Patient biographies and life trajectories are not always relevant to this work of ongoing monitoring and surveillance, and the opportunities to explore personal history are extremely limited. When they are provided, through group activities, this can be counterproductive when the immediate group relations are not related to past 
experiences and relationships (such as experiences of sexual violence or abuse). What patients in our study clearly demonstrate, in different ways, is that a relationship to the past is crucial to a sense of agency in the present and future. What this suggests is the need to think of patient engagement with the therapeutic landscape of the ward as defined by temporal as well as spatial boundaries. As Lewin (1997) described, the psychological field includes relevant aspects of the past as well as imagined aspects of the future. Supporting patients in the capacity to relate to what is happening to them now in a broader trajectory of experience is critical to promoting what Duff (2016) terms an 'atmosphere of recovery'. Patients need to be able to develop an active relationship to past places and relationships in order to explore their current and future significance. This means developing practice where the past can be mobilised as a 'live' feature of the present.

Personal space, where patients feel their own individual needs can be expressed and addressed, rarely emerges on the ward. Mental health service users on a forensic pathway may move across a number of institutions, from prisons to high and medium secure units, before eventually transitioning into low secure care and then care within the community. There is no ready practical means for service users to record and reflect on the meaning of their institutional journey, despite relationships with staff encountered along the way having great value in terms of feeling 'personally known'. Forensic psychiatric care is not unique in terms of issues around transitions between numerous settings, both in health and social care. Similar issues exist around child welfare in state care and adoption and in geriatric care. There 'life story 
work' (where the past, present and future hopes are recorded using photographs and diaries) is typically used to assist in both informing carers and allowing the client to make sense of their experience over time (Shotton, 2013). Practices such as this might have promise in psychiatric settings as means of supporting a meaningful life trajectory. As the empirical material presented here shows, when patients are unable to reflect upon the place of detention in relation to their life, they are likely to develop idealised and most likely unfeasible views of their future (such as the resumption of the past as it once was). Creating a liveable psychological space in secure psychiatric settings then involves considerably more than just extending the physical space of the ward: it needs to start from a sense of the relations that go way beyond the here and now of the patient's present.

\section{Conclusion}

This paper has contributed to the body of work that explores the unique character of secure psychiatric care in the UK within the 'post-asylum' landscape (Curtis et al, 2013; Moon et al, 2015; Wolch \& Philo, 2000; Quirk et al, 2006). In the units where this care is provided, the traditional role of the asylum as balancing risk through physical separation of patients from the community with the provision of care remains a live project. We have shown that measures to improve the therapeutic landscape of one specific unit, through interventions aimed at creating a greater sense of physical movement and liberty, had the reverse effect of narrowing a felt sense of agency. We have argued that adopting a relational approach, where relations are seen as 
extending both spatially and temporally in a topological manner, allows us to better understand the 'relational dynamics' (cf. Moon et al, 2015) that afford specific experiences of recovery. We propose that designing both the built environment and the practices for delivering care on the basis of a 'relational mapping' of patient experiences could significant enhance the capacity to support 'secure recovery'.

\section{References}

Amar Shah, Gerard Waldron, Neil Boast, Jeremy W. Coid \& Simone Ullrich (2011) Factors associated with length of admission at a medium secure forensic psychiatric unit, The Journal of Forensic Psychiatry \& Psychology, 22:4, 496-512, DOI: 10.1080/14789949.2011.594902

Bell SL, Foley R, Houghton F, Maddrell A, Williams A (2017). From therapeutic landscapes to healthy spaces, places and practices: a scoping review. Social Science and Medicine, 196, 123-130 DOI: https://doi.org/10.1016/j.socscimed.2017.11.035

Bolton, A., Pole, C., \& Mizen, P. (2001). Picture this: researching child workers. Sociology, 35: 501-518, DOI: https://doi.org/10.1177/S0038038501000244

Brown, K \& Fahy,T (2009) Medium secure units: pathways of care and time to discharge over a four-year period in South London, The Journal of Forensic Psychiatry \& Psychology, 20:2, 268277, DOI: $\underline{10.1080 / 14789940802327291}$ 
Brown, S.D., Cromby, J., Harper, D., Johnson, K., \& Reavey, P. (2011).

Researching "experience": embodiment, methodology, process. Theory \& Psychology, 23: 493-515. DOI:

https://doi.org/10.1177/0959354310377543

Brown, S.D., Reavey, P. (2015). Vital memory and affect: Living with a difficult past. London: Routledge.

Brown, S.D. Reavey, P., Kanyeredzi, A. \& Batty, R. (2014). Transformations of self and sexuality: psychiatric inpatients accounts of sexuality and relationships. Health, 18, 240-260.

Coid, J., Kahtan, N., Gault, S., Cook, A. and Jarman, B. 2001. Medium secure forensic psychiatry services: Comparison of seven English health regions. British Journal of Psychiatry, 178: 55-61. DOI: https://doi.org/10.1192/bjp.178.1.55.

Coleman, T. \& Kearns, R. (2015) The role of bluespaces in experiencing place, aging and wellbeing: Insights from Waiheke Island, New Zealand. Health \& Place, 35: 206-217.

https://doi.org/10.1016/j.healthplace.2014.09.016

Connellan, K., Gaardboe, M., Riggs, D., Due., Reinschmidt, A. \& Mustillo, L. (2013). Stressed spaces: Mental health and architecture. HERD: Health Environments Research and Design Journal, 6(4), 127-168. DOI: https://doi.org/10.1177/193758671300600408 
Creswell, J. \& Miller, D.J. (2000). Determining Validity in Qualitative Inquiry. Theory into Practice, 39: 123-130. DOI: https://doi.org/10.1207/s15430421tip3903 2

Cromby, J. (2015). Feeling bodies, embodying psychology. Basingstoke: Palgrave Macmillan.

Cromby, J., Harper, D. \& Reavey, P. (2013). Psychology, Mental Health and Distress. Basingstoke: Palgrave Macmillan.

Curtis, S. (2010). Space, place and mental health. London: Routledge.

Curtis, S., Gesler, W., Fabian, K., Francis, S., \& Priebe, S. (2007). Therapeutic landscapes in hospital design: a qualitative assessment by staff and service users of the design of a new mental health inpatient unit. Environment and Planning C: Government and Policy, 25, 591610. DOI: https://doi.org/10.1068/c1312r

Curtis, S., Gesler, W., Priebe, S. \& Francis, S. (2009). New spaces of inpatient care for people with mental illness: A complex 'rebirth' of the clinic? Health \& Place, 15, 340-348. DOI: https://doi.org/10.1016/j.healthplace.2008.06.007

Curtis, S.E., Gesler, W., Wood, V., Spencer, I., Mason, J., Close, H. \& Reilly, J. (2013). Compassionate containment? Balancing technical safety and therapy in design of psychiatric wards. Social Science \& Medicine, 97, 201-209. DOI: http://dx.doi.org/10.1016/i.socscimed.2013.06.015

Department of Health (2009). New Horizons: Towards a shared vision for mental health - consultation. London: Department of Health. 
Department of Health (2011). No health without mental health: A crossgovernmental outcomes strategy for people of all ages. London: Department of Health.

Dernevik, M., Grann, M. \& Johansson, S. ( 2002) Violent behaviour in forensic psychiatric patients: Risk assessment and different risk-management levels using the HCR-20, Psychology, Crime and Law, 8:1, 93-111. DOI: https://doi.org/10.1080/10683160208401811

Drennan, G. \& Aldred, D. (2012). Recovery in forensic mental health settings: From alienation to integration. In G. Drennan \& D. Aldred (Eds.), Secure recovery: Approaches to recovery in forensic mental health settings. London: Routledge.

Drennan G. and Wooldridge, J (with Aiyegbusi, A., Alred, D., Ayres, J., Barker, R., Carr, S., Eunson, H., Lomas, H., Moore, E., Stanton, D. \& Shepherd, G.) (2014) Making Recovery a Reality in Forensic Settings. London, Centre for Mental Health and Mental Health Network, NHS Confederation.

Duff, C. (2012). Exploring the role of enabling places in promoting recovery from mental illness: A qualitative test of a relational model. Health \& Place, 18(6), 1388-1395.

Duff, C. (2016). Atmospheres of recovery: Assemblages of health. Environment and Planning A, 48(1), 58-74.

Edwards, J., Steed, P., \& Murray, K. (2002). Clinical and forensic outcome 2 years and 5 years after admission to a medium secure unit. The 
Journal of Forensic Psychiatry, 13(1), 68-87. DOI:

https://doi.org/10.1080/09585180210123294.

Foucault, M. (1995) Discipline \& Punish: The Birth of the Prison. London: Vintage Books.

Gesler, W. (2003). Healing places. Lanham, MD: Rowman \& Littlefield.

Gillies, V., Harden, A., Johnson, K., Reavey, P., Strange, V., Willig, C. (2004).

Women's collective constructions of embodied practices through memory work: Cartesian dualism in memories of sweating and pain. British Journal of Social Psychology, 43: 99 -112. DOI: https://doi.org/10.1348/014466604322916006

Gillies, V., Harden, A., Johnson, K., Reavey, P., Strange, V., Willig, C. (2005). Painting pictures of embodied experience: the use of nonverbal data production for the study of embodiment. Qualitative Research in Psychology, 2: 1-13. DOI: https://doi.org/10.1191/1478088705qp038oa

Gudjonsson, G. H., Webster, G., \& Green, T. (2010). The recovery approach to care in psychiatric services: staff attitudes before and after training. The Psychiatrist, 34(8), 326-329. DOI: https://doi.org/10.1192/pb.bp.109.028076

Heft, H. (2001). Ecological psychology in context. New York: Psychology Press.

Kearns, R. \& Moon, G. (2002). From medical to health geography: Novelty, place and theory after a decade of change. Progress in Human Geography, 26(5), 605-625. 
Knight, V. (2016). Remote control: Television in prison. Basingstoke: Palgrave Macmillan.

Knowles, C. (2000a). Bedlam on the streets. London: Routledge.

Knowles, C. (2000b). Burger King, Dunkin Donuts and community mental health care, Health \& Place, 6: 213-224. DOI: https://doi.org/10.1016/S1353-8292(00)00024-1

Lawson, B, Phiri, M., \& Wells-Thorpe, J. (2003). The architectural healthcare environment and its effects on patient health outcomes: $A$ report on an NHS Estates funded research project. London: The Stationary Office.

Leamy M., Bird V., \& Le Boutillier, C. (2011). Conceptual framework for personal recovery in mental health: Systematic review and narrative synthesis. British Journal of Psychiatry, 199, 445-452. DOI: https://doi.org/10.1192/bjp.bp.110.083733

Lewin, K (1936). Principles of topological psychology. New York: McGraw Hill. Lewin, K. (1997). Resolving social conflicts and field theory in social science. Washington: American Psychological Association.

Maden, T. (2007). Treating violence: a guide to risk management in mental health. Oxford: Oxford University Press.

Malpas, J. (2012). Putting space in place: Philosophical topography and relational geography. Environment and Planning D: Society and Space, 30(2), 226 - 242. DOI: https://doi.org/10.1068/d20810

Massey, D. (2005). For space. London: Sage. 
McGrath, L. (2012). Heterotopias of mental health care: The role of space in experiences of distress, madness and mental health service use. Unpublished PhD thesis submitted to London South Bank University.

McGrath, L., \& Reavey, P. (2013). Heterotopias of control: Placing the material in experiences of mental health service use and community living. Health and Place, 22: 123-131.

DOI:10.1016/j.healthplace.2013.03.010

McGrath, L., Reavey, P. (2015). Seeking fluid possibility and solid ground: Space and movement in mental health service users' experiences of 'crisis', Social Science and Medicine, 128, 115-125. DOI: https://doi.org/10.1016/j.socscimed.2015.01.017

Mezey et al, 2010: Gillian C. Mezey, Michael Kavuma, Penny Turton, Alexia Demetriou \& Christine Wright(2010) Perceptions, experiences and meanings of recovery in forensic psychiatric patients, The Journal of Forensic Psychiatry \& Psychology, 21:5, 683-

696, DOI: $\underline{10.1080 / 14789949.2010 .489953}$

Miles, H. (2012). 'Supporting recovery' and 'moving on' - the recovery approach applied to group intervention programme in in-patient settings. In G. Drennan \& D. Aldred (Eds.), Secure recovery: Approaches to recovery in forensic mental health settings. London: Routledge.

Moon, G. (2000). Risk and protection: The discourse of confinement in contemporary mental health policy. Heath \& Place, 6, 239-250. 
Moon, G., Kearns, R., \& Joseph, A. (2015) The Afterlives of the Psychiatric Asylum: Recycling concepts, sites and memories. Farnham: Ashgate.

Moran, D. (2015) Carceral Geography: Spaces and practices of incarceration. Farnham: Ashgate.

NAPICU (2017). Design Guidance for Psychiatric Intensive Care Units.

NHS England (2016). The five year forward view for mental health: A report from the independent mental health taskforce to NHS in England.

Quirk, A., Lelliott, P. \& Seale, C. (2006). The permeable institution: An ethnographic study of three acute psychiatric wards in London. Social Science \& Medicine, 63, 2105-2117. DOI: https://doi.org/10.1016/j.socscimed.2006.05.021

Papoulias, C., Csipke, E., Rose, D., McKellar, S., \& Wykes, T. (2014). The psychiatric ward as a therapeutic space: Systematic review. British Journal of Psychiatry, 205(3), 171-176. DOI: https://doi.org/10.1192/bjp.bp.114.144873

Parr, H. \& Philo, C. (1996). 'A Forbidding Fortress of Locks, Bars and Padded Cells': The locational history of mental health care in Nottingham. Historical Geography Research Series, 32.

Payne, H. \& May, D. (2009). Evaluation of a refurbishment scheme incorporating the King's Fund 'Enhancing the Healing Environment' design principles. Journal of Facilities Management, 7(1), 74-89.DOI: https://doi.org/10.1108/14725960910929583 
Philo, C. (1987). 'Fit localities for an asylum': The historical geography of the mad-business in England as viewed through the pages of Asylum Journal. Journal of Historical Geography, 13, 398-415.

Philo, C. (1995). Journey to asylum: A medico-geographical idea in historical context. Journal of Historical Geography, 21, 148-168.

Philo, C. (1997). Across the water: Reviewing geographical studies of asylums and other mental health facilities. Health \& Place, 3(2), 79-89.

Reavey, P. (2010). Spatial markings: Memory, agency and child sexual abuse, Memory Studies, 3: 314-329. DOI: https://doi.org/10.1177/1750698010370035

Reavey, P. (Ed.) (2011). Visual methods in Psychology: Using and interpreting images. London: Routledge.

Reavey, P., Prosser, J. (2012). Visual research in Psychology. In H. Cooper, P. M. Camic, D. L. Long, A. T. Panter, D. Rindskopf,, K. J. Sher, (Eds). APA handbook of research methods in psychology, Vol 2: Research designs: Quantitative, qualitative, neuropsychological, and biological. Washington: American Psychological Association.

Reavey, P., Harding, K \& Bartle, J. (2017) Design with People in Mind. Design in Mental Health Network, UK.

Reavey, P., Poole, J., Ougrin, D. et al, (2017). The Ward as Emotional Ecology: Adolescent experiences of managing emotional distress in inpatient settings. Health \& Place, 46, 210-218. DOI: https://doi.org/10.1016/j.healthplace.2017.05.008

Reavey, P. \& Johnson, K. (2017). Visual Methods: Using and Interpreting Images. In C. Willig \& W. Stainton-Rogers (Eds.) The Sage Handbook 
of Qualitative Methods in Psychology (2nd Edition). London: Sage. Reavey, P., Brown, S.D., Poole, J. \& Ravenhill, J. (forthcoming) Sexuality, Risk, and Organizational Misbehavior in a Secure Mental Healthcare Facility in England. Qualitative Health Research.

Roberts, G., Dorkins, E., Wooldridge, J., \& Hewis, E. (2008). Detained-what's my choice? Part 1: Discussion. Advances in Psychiatric Treatment, 14(3), 172-180. DOI: https://doi.org/10.1192/apt.bp.107.003533

Rose, G. (2001). Visual methodologies: An introduction to the interpretation of visual materials. London: Sage.

Scheel, K.R. (2000). The empirical basis of Dialectical Behaviour Therapy: Summary, critique and implications. Clinical Psychology: Science and Practice, 7(1), 68-86.

Shotton, G. (2013). 'Remember when...': exploring the experiences of looked after children and their carers in engaging in collaborative reminiscence. Adoption \& Fostering, 37(4), 352-367. DOI: https://doi.org/10.1177/0308575913508721

Smith, J. \& Garcia, V. (2012). Recovering personhood: Using recovery principles on a long-stay medium secure ward. In G. Drennan \& D. Aldred (Eds.), Secure recovery: Approaches to recovery in forensic mental health settings. London: Routledge. 
Stenner, P. (1993). Discoursing jealousy, in E. Burman \& I. Parker (Eds.) Discourse analytic research: repertoires and readings of texts in action. London: Routledge.

Stenner, P. (2017). Liminality and experience: $A$ transdisciplinary approach to the psychosocial. Basingstoke: Palgrave macmillan.

Stenner, P. \& Brown, S.D. (2009). Psychology without foundations: History, philosophy and psychosocial theory. London: Sage.

Taylor, L. \& Cohen, S. (1972). Psychological Survival: The experience of longterm imprisonment. Harmondsworth: Pelican.

Tucker, I. (2010). Mental health service user territories: Enacting 'safe spaces' in the community. Health, 14, 434-448. DOI:

\section{https://doi.org/10.1177/1363459309357485}

Warner, S. (2009). Understanding child sexual abuse: Feminist revolutions in theory, research and practice. London: Routlege.

Williams, T., Leamy, M., Bird, V., et al (2012). Measures of the recovery orientation of mental health services: systematic review, Social Psychiatry and Psychiatric Epidemiology, 47, 1827-1835. DOI: https://doi.org/10.1007/s00127-012-0484-y

Willig, C. (2008). An introduction to qualitative research in psychology: adventures in theory and method (2 ${ }^{\text {nd }}$ Edition). London: Sage. 
Wolch, J. \& Philo, C. (2000) From distributions of deviance to definitions of difference: Past and future mental health geographies. Health and Place, 6(3), 137-157.

Wood, V.J., Curtis, S.E., Gesler, W, Spencer, I.H., Close, H.J., Mason, J., \& Reilly, J.G. (2013). Creating 'therapeutic landscapes' for mental health carers in inpatient settings: A dynamic perspective on permeability and inclusivity. Social Science \& Medicine, 91: 122-129. DOI: https://doi.org/10.1016/j.socscimed.2012.09.045

Wood, V.J., Gesler, W., Curtis, S.E., Spencer, I.H., Close, H.J., Mason, J., \& Reilly, J.G. (2015). 'Therapeutic landscapes' and the importance of nostalgia, solastalgia, salvage and abandonment for psychiatric hospital design. Health \& Place, 33, 83-89. DOI: https://doi.org/10.1016/j.healthplace.2015.02.010 